See discussions, stats, and author profiles for this publication at: https://www.researchgate.net/publication/316247269

\title{
Larvicidal effectiveness of acethonilic and methanolic Ipomoea cairica extract using two extraction methods and its effects on the morphology of Culex quinquefasciatus Say mosquito
}

Article in Oriental Insects · April 2017

DOI: 10.1080/00305316.2017.1316785

\section{CITATIONS}

3

6 authors, including:

Wan Fatma Zuharah

Universiti Sains Malaysia

67 PUBLICATIONS 445 CITATIONS

SEE PROFILE

Zary S Yahaya

Universiti Sains Malaysia

50 PUBLICATIONS 157 CITATIONS

SEE PROFILE
READS

133

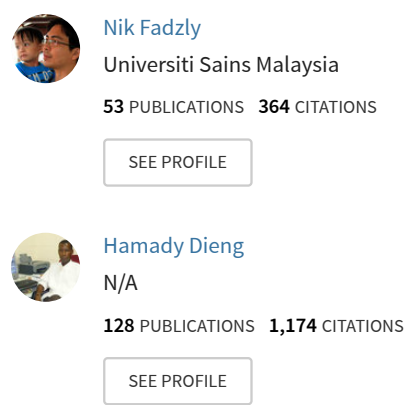

Some of the authors of this publication are also working on these related projects:

Primate conservation and general conservation issues in Malaysia View project

Epidemiology of urinary schistosomiasis and knowledge of health personnel in rural communities of south-western Nigeria View project 


\section{Larvicidal effectiveness of acethonilic and methanolic Ipomoea cairica extract using two extraction methods and its effects on the morphology of Culex quinquefasciatus Say mosquito}

Wan Fatma Zuharah, Maniam Thiagaletchumi, Nik Fadzly, Sreeramanan Subramaniam, Zary Shariman Yahaya \& Hamady Dieng

To cite this article: Wan Fatma Zuharah, Maniam Thiagaletchumi, Nik Fadzly, Sreeramanan Subramaniam, Zary Shariman Yahaya \& Hamady Dieng (2017): Larvicidal effectiveness of acethonilic and methanolic Ipomoea cairica extract using two extraction methods and its effects on the morphology of Culex quinquefasciatus Say mosquito, Oriental Insects, DOI: 10.1080/00305316.2017.1316785

To link to this article: http://dx.doi.org/10.1080/00305316.2017.1316785

曲 Published online: 18 Apr 2017.

Submit your article to this journal $₫$

View related articles $\nearrow$

View Crossmark data $\nearrow$ 


\title{
Larvicidal effectiveness of acethonilic and methanolic Ipomoea cairica extract using two extraction methods and its effects on the morphology of Culex quinquefasciatus
}

\section{Say mosquito}

\author{
Wan Fatma Zuharaha,b (D), Maniam Thiagaletchumia, Nik Fadzlya,b (D), \\ Sreeramanan Subramaniam ${ }^{a}$ (D) Zary Shariman Yahaya ${ }^{a}$ (D) and Hamady Dieng ${ }^{c}$

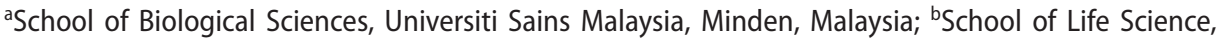 \\ Keele University, Keele, UK; Institute of Biodiversity and Environmental Conservation, Universiti \\ Malaysia Sarawak, Kota Samarahan, Malaysia
}

\begin{abstract}
Plants produce a rich source of chemicals, drugs and secondary metabolites that can act as insect killer. The larvicidal activity of various part of Ipomoea cairica extracts was evaluated against Culex quinquefasciatus. The highest percentage of yield extract was given by Soxhlet with acetone solvent for all of the different plant parts. While, maceration technique only provided $1 / 3$ of the yield compared to Soxhlet technique. Using $24 \mathrm{~h}$ larvicidal bioassay technique, third instar larvae of $C x$. quinquefasciatus were exposed to concentrations ranging from 10 to 600 ppm of the acetone and methanol extracts of $I$. cairica from leaves, stem and flower bud. Acethonilic extract of I. cairica leaves was extracted using a Soxhlet apparatus which exhibited the most promising larvicidal activity against $C x$. quinquefasciatus larvae with significantly lower $\mathrm{LC}_{50}$ value of 110.65 ppm, meanwhile methanolic leaves extract exhibited $\mathrm{LC}_{50}$ value of $143.47 \mathrm{ppm}$. Larvae exposed to the I. cairica extracts for $24 \mathrm{~h}$ showed morphological malformation that included a detachment of thorax, disruption of the digestive tract and pigmentation of cuticle on their death. Thus, suggested that $I$. cairica plant extract, especially acethonilic leaves extract can be considered as one of plant-derived insecticides for control of $C x$. quinquefasciatus, a vector of filariasis.
\end{abstract}

\section{ARTICLE HISTORY}

Received 18 July 2016

Accepted 4 April 2017

\section{KEYWORDS}

Biological control; Culex quinquefasciatus; larvicidal efficacy; mosquito; plant extract

\section{Introduction}

Mankind has been plagued by mosquito nuisance and mosquito-borne diseases since ages, resulting in various health problems and economic losses. Mosquito transmits some of the deadliest diseases known to man, such as 
malaria, yellow fever, dengue, encephalitis, filariasis and a hundred or so other infectious diseases, claiming many millions of lives. The risk of infection exists all year and can be fatal if left untreated. Culex quinquefasciatus Say is one the most abundant tropical house mosquito (AbuHassan \& Che Salmah 1990) and it is also one of the major vectors for human lymphatic filariasis, caused by nematode Wuchereria bancrofti (Harwood \& James 1979) An estimated 120 million people in 73 countries are currently infected, and an estimated 1.393 billion live in areas where filariasis is endemic (WHO 2012). Due to the lack of awareness among people, early detection and complete treatment of this disease are very difficult.

Vector control is still one of the primary weapons to combat mosquito spread diseases in endemic areas. Synthetic chemical larvicides and adulticides are still the major sources in controlling the mosquito's population in most parts of the world (Rahuman et al. 2009). The primary environmental difficulty with the use of chemical control is that often pesticides are applied directly into residential areas and into sensitive natural environments. The risks of pesticide are also associated with the acute and chronic pesticide impacts to humans, wildlife and other non-target species, the persistence of certain pesticides in the environment and the transport of pesticides outside target areas, which can cause unintended environmental damage. The intensive use of insecticides has also resulted in the emergence and spread of resistance to organophosphorus (OP) (Karunaratne \& Hemingway 2001), carbamate (Vaughan et al. 1998) and pyrethroid insecticides (Mebrahtu et al. 1997; Brengues et al. 2003) and this resistance problem shifted the mosquito control programme to the use of environmental friendly, biodegradable and safer alternative insecticides of plant origin.

The search for natural products as an alternative to synthetic insecticides for the control of destructive insects and vectors of diseases is desirable due to the prevalent occurrence of vector resistance, toxic and non-biodegradable residues contaminating the environment and undesirable effects on non-target organisms (Jantan et al. 2005). Botanical insecticides are safe and degradable, and effective alternatives to conventional synthetic insecticide (Nathan et al. 2004). Many studies have reported the application of the potential plant extracts or essential oil on mosquito larvae. The extract of Vitex trifolia (Kannathasan et al. 2007), the petroleum ether-acetone extract of Calotropis gigantean (Neraliya \& Srivastava 1996), the methanolic extracts of Solanum suratense, Azadirachta indica, and Hydrocotyle javanica (Muthukrishnan et al. 1997), the essential oil of Zingiber officinalis Linn (Zingiberaceae) (Pushpanathan et al. 2008) exhibited larvicidal activity against the larvae of $C x$. quinquefasciatus. Rhinacanthus nasutus dried root powder methanol extracts (Rongsriyam et al. 2006), petroleum ether extract of Solanum xanthocarpum fruit (Rahuman \& Venkatesan 2008), leaf extract of Ageratina. Adenophora (Mohan \& Ramaswamy 2007) showed acute toxicity against the larvae of Ae. aegypti and Cx. quinquefasciatus. Acetone and methanol extracts of Canna indica 
$\mathrm{L}$ also have been reported to have larvicidal activity against $C x$. quinquefasciatus (Rahuman et al. 2009).

Regardless, researchers are often confronted with the challenge of extracting the plant material in order to study on biological activities associated with a plant or a plant extract. Sample preparation is a crucial first step in the analysis of plant materials. Different extraction techniques have been developed to exploit plant material resources and to obtain such valuable products (Chemat et al. 2004). The process of extraction of active substances from a plant material by means of a solvent generally occurs in two main stages: first, dissolution of material near the surface (so-called washing or fast extraction) and second, diffusion of the solute from the porous plant residue into the solution (so-called slow extraction) (Smelcerovic et al. 2006). The extraction relies primarily on the solubilisation of metabolites and by increasing the temperature to favour solubilisation (Jones \& Kinghorn 2006). The right choice of extraction procedure is necessary to extract the desired chemical components from the studied plant for further analysis.

Therefore, the present study aimed to explore two commonly employed plant extraction methods; maceration and Soxhlet with two different solvents; acetone and methanol, in order to evaluate the larvicidal activity of various parts; leaves, stems, and flower buds of Ipomoea cairica Linn (Convolvulaceae) crude extract against $C x$. quinquefasciatus larvae. The yield percentage of plant extracts based on the above methods and solvents were also determined.

\section{Materials and methods}

\section{Mosquito colonies}

Culex quinquefasciatus larvae were collected from stagnant water area of Bagan Dalam, Penang, Malaysia ( $5^{\circ} 24^{\prime} 00^{\prime \prime} \mathrm{N}, 100^{\circ} 23^{\prime} 00^{\prime \prime} \mathrm{E}$ ). The larvae were kept in enamel trays containing dechlorinated tap water. In order to have standard age and size of third instar larvae used in this study, we need to culture the mosquitoes until F1 generation. The larval density was maintained at first larva to $20 \mathrm{~mL}$ dechlorinated tap water per tray. Larvae were fed with a fine powder mixture of dog biscuit, beef liver, yeast and milk powder in the ratio of 2:1:1:1 by weight. Pupae were transferred into plastic containers and were maintained in a mosquito cage to emerge. Adults were continuously provided with $10 \%$ sucrose solution in a $50 \mathrm{~mL}$ conical flask with a cotton wick. On day five, the adults were given a blood meal of laboratory blood mice overnight. A bowl with $50 \mathrm{~mL}$ of chlorine free water was kept inside the cage for oviposition. Egg rafts were observed to hatch and were transferred to enamel trays. Larval rearing and all experiments were conducted under laboratory conditions at a temperature $\left(28 \pm 2{ }^{\circ} \mathrm{C}\right)$ and $(80 \pm 10 \%)$ relative humidity $(\mathrm{RH})$. This project has been approved by the Animal Ethic Committee, Universiti Sains, Malaysia. However, the animal care permit is not requires for this kind of study. 


\section{Plant collection}

Leaves, stems and flower buds samples of I. cairica were collected from residential areas in Relau, Penang, Malaysia $\left(5^{\circ} 25^{\prime} 00^{\prime \prime} \mathrm{N} 100^{\circ} 19^{\prime} 00^{\prime \prime} \mathrm{E}\right)$ by utilising a random sampling method and were identified by the Botanical Department of Universiti Sains, Malaysia. All of the plant parts were air dried at room temperature for 1-2 weeks until its weight remained constant. The dried plant parts were then powdered mechanically using electrical stainless steel blender (Panasonic: MX-899TM). This increases the surface area for extraction, hence increasing the rate of extraction (Elango et al. 2011). The sample was then kept under room temperature in a labelled airtight container. Two different extraction methods were used in this experiment; maceration and Soxhlet with two different solvents; methanol and acetone.

\section{Maceration extraction}

An amount of $60 \mathrm{~g}$ of dried leaves powder was measured and placed in a beaker. One litre of either methanol or acetone solvent were added into the beaker and the sample was left to macerate for $7 \mathrm{~d}$, until the cellular structure of the plant sample was softened, penetrated by the solvent and the soluble components were dissolved. The plant sample in the solvent was occasionally stirred to facilitate the speed of extraction. After the procedure was done, the extract obtained will be a mixture of solvent, extract and sample waste. The extract was then filtered with Whatman filter paper No. 1 to remove the sample waste and then evaporated in a rotary vacuum evaporator in order to have crude extract. The same procedures were repeated once to give a total of $120 \mathrm{~g}$ of plant powder macerated in $2 \mathrm{~L}$ of solvent and the process was also repeated for dried powdered stems and flower buds.

\section{Soxhlet extraction}

For extraction using a Soxhlet apparatus (Favorit, Malaysia), $120 \mathrm{~g}$ of dried plant powder was weighed and placed into the paper thimble. Small stones were placed in between the powdered plant sample, to enhance the extraction as it allowed better filtration. As a precaution method cotton wool was placed on top and bottom part of the extraction flask to prevent the sample from entering other parts of the apparatus. Methanol and acetone were used as chemical solvent as these solvents exist as a polar liquid at room temperature was experimented separately. Two litres of solvent were placed in a round-bottom flask with the heating mantle underneath. The round-bottom flask and the extractor were covered with muslin cloth for better heat absorption. The solvent was heated and refluxing solvent repeatedly washed the fine grind plant material extracting the desired compound into the round-bottom flask. The extraction in the Soxhlet apparatus with the boiling point at $70{ }^{\circ} \mathrm{C}$ was done for about $3 \mathrm{~h}$ until the solution of the extract and solvent in the siphon arm becomes clear which indicates the sample has 
been extracted entirely. The extract was then evaporated to dryness in the rotary vacuum evaporator. The same procedures were repeated using dried, powdered stems and flower buds of the studied plant.

\section{Drying the extract}

In order to remove the solvent from the crude extract, the extract collected in the round-bottom flask was then evaporated in a rotary vacuum evaporator. The boiling point of methanol and acetone were 66 and $50.5^{\circ} \mathrm{C}$, respectively. The temperature of the water bath was set to $55^{\circ} \mathrm{C}$ with 100 rounds per minute. The extract collected was then poured into a petri dish and placed in the oven at $37^{\circ} \mathrm{C}$ for $24 \mathrm{~h}$ to evaporate any leftover solvent and the crude extract obtained was in the form of a paste. The weight of the crude extract was measured to determine the percentage of yield and was then preserved in petri dishes at $4{ }^{\circ} \mathrm{C}$ until further use.

\section{Larvicidal bioassay}

The larvicidal bioassay was done according to the WHO (2005) standard procedures. A stock solution was prepared by dissolving one gram of crude extract in $100 \mathrm{ml}$ of solvent and subsequently serial dilutions were done to prepare concentration ranging from 10 to $600 \mathrm{ppm}$. A total of 25 numbers of late third instar larvae was placed in paper cups with the different concentration the plant extract with a total of $250 \mathrm{ml}$ (declorinated water and plant extract). About $1 \mathrm{ml}$ of $10 \%$ solvent in $249 \mathrm{ml}$ distilled water was served as control. The larval mortality was observed after $24 \mathrm{~h}$ post-treatment. Dead larvae are those that are insensitive to probe with a needle and moribund larvae are those incapable of rising to the surface for respiration (WHO 2005). The experiment was replicated four times for each concentration.

\section{Statistical analysis}

We used MANOVA to test the significant effects of different plant parts, concentrations, methods of extractions and solvents on CX. quinquefasciatus larval mortality using SPSS version 16.0. Data were tested for normality using KolomogorovSmirnov test and were log-transformed $(y+1)$ prior to analysis to satisfy the assumption of ANOVA. Results of larval mortality on different concentration were tested using probit analysis in order to have lethal concentration $50\left(\mathrm{LC}_{50}\right)$ and lethal concentration $95\left(\mathrm{LC}_{95}\right)$. Data were log-transformed (log 10) in order to satisfy the assumption of probit analysis.

The percentage of the yield in this study was determined by the formula,

$$
\text { Percentage of yield }=\frac{\text { Paste }(\mathrm{g})}{\text { Dried plant powder }(\mathrm{g})} \times 100 \% \text {. }
$$




\section{Results}

Different extraction techniques and solvents used to obtain the crude extract of I. cairica plant parts, showed significant effect on the mortality of $C x$. quinquefasciatus larvae ( $F=32.56, \mathrm{df}=1, p<0.05$; Table 1$)$. Soxhlet had proven to provide higher extraction efficiency compared to maceration based on the percentage yield of I. cairica crude extracts (Figure 1). The highest yield was obtained from the leaves

Table 1. Effects of different plant parts, solvents and extraction methods studied on Ipomoea cairica crude extracts against Culex quinquefasciatus larvae.

\begin{tabular}{lrrrr}
\hline Source & df & MS & F-ratio & \multicolumn{1}{c}{ Sig. } \\
\hline Plant parts $(P)$ & 2 & 1.149 & 24.989 & $<0.001$ \\
Solvent $(S)$ & 1 & 8.812 & 191.638 & $<0.001$ \\
Concentration $(C)$ & 10 & 58.418 & 1270.451 & $<0.001$ \\
Extraction method $(E)$ & 1 & 3.463 & 75.303 & $<0.001$ \\
$P \times S$ & 2 & 0.092 & 2.001 & 0.137 \\
$P \times C$ & 20 & 0.129 & 2.808 & $<0.001$ \\
$P \times E$ & 2 & 0.671 & 14.597 & $<0.001$ \\
$S \times C$ & 10 & 0.593 & 12.889 & $<0.001$ \\
$S \times E$ & 1 & 1.497 & 32.556 & $<0.001$ \\
$C \times E$ & 10 & 0.348 & 7.574 & $<0.001$ \\
$P \times S \times C$ & 20 & 0.055 & 1.194 & 0.255 \\
$P \times S \times E$ & 2 & 0.474 & 10.312 & $<0.001$ \\
$P \times C \times E$ & 20 & 0.238 & 5.176 & $<0.001$ \\
$S \times C \times E$ & 10 & 0.239 & 5.204 & $<0.001$ \\
$P \times S \times C \times E$ & 20 & 0.072 & 1.564 & 0.058 \\
Error & 396 & 0.046 & &
\end{tabular}

Note: df-degree of freedom; MS-mean square, Significant values are in bold.

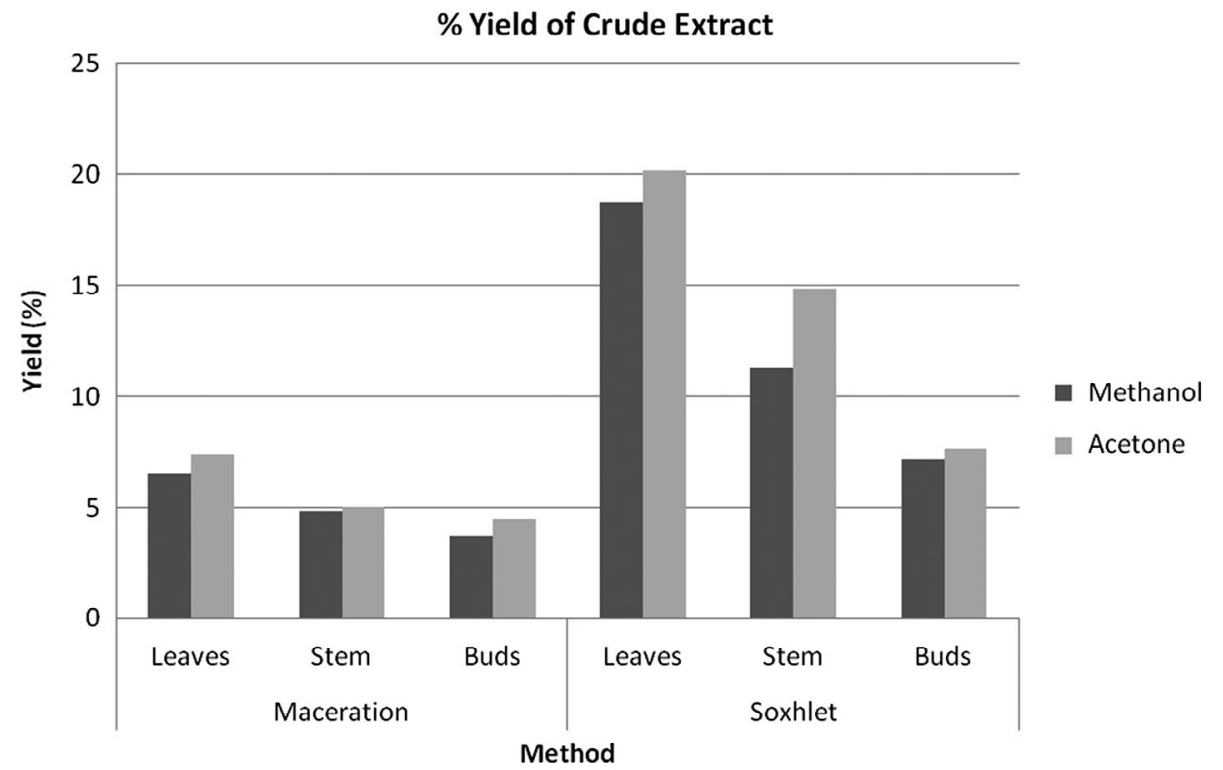

Figure 1. Percentage of yield obtained from different plant parts of Ipomoea cairica crude extract using different method of extractions and solvents. 
of the $I$. cairica using the Soxhlet technique with acetone as solvent at $20.16 \%$, and followed by methanol at $18.75 \%$. The maceration method only extracted 7.43 and $6.54 \%$ for acetone and methanol, respectively from the leaves of the studied plant (Figure 1). Subsequently, for the extraction of stem and flower buds, Soxhlet technique also gives better yield compared to the maceration method, but the yield was lesser than leaves for both solvent used; acetone and methanol.

Considerable differences in larvicidal efficacy of the plant extracts obtained from the different extraction methods were indicated by the results from this study, extracts obtained from Soxhlet found to be more active than extracts from maceration method (Figures 2 and 3). The study also revealed that for both the extraction method; maceration and Soxhlet, acetone extract of leaves indicated the highest larvicidal activity towards $C x$. quinquefasciatus larvae with significantly lower LC50 values at 129.564 and $110.653 \mathrm{ppm}$, respectively $(F=32.56$, $\mathrm{df}=1, p<0.05$; Table 1 ) after 24 h exposure. While, acetone extract of flower buds

(A) Larval mortality caused by methanol extracts.

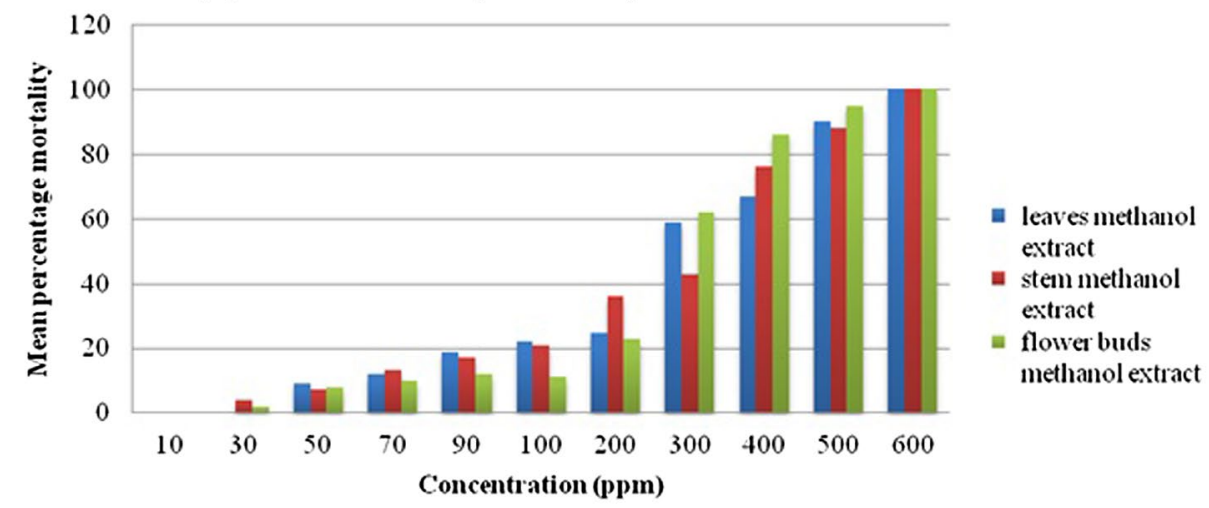

(B) Larval mortality caused by acetone extracts.

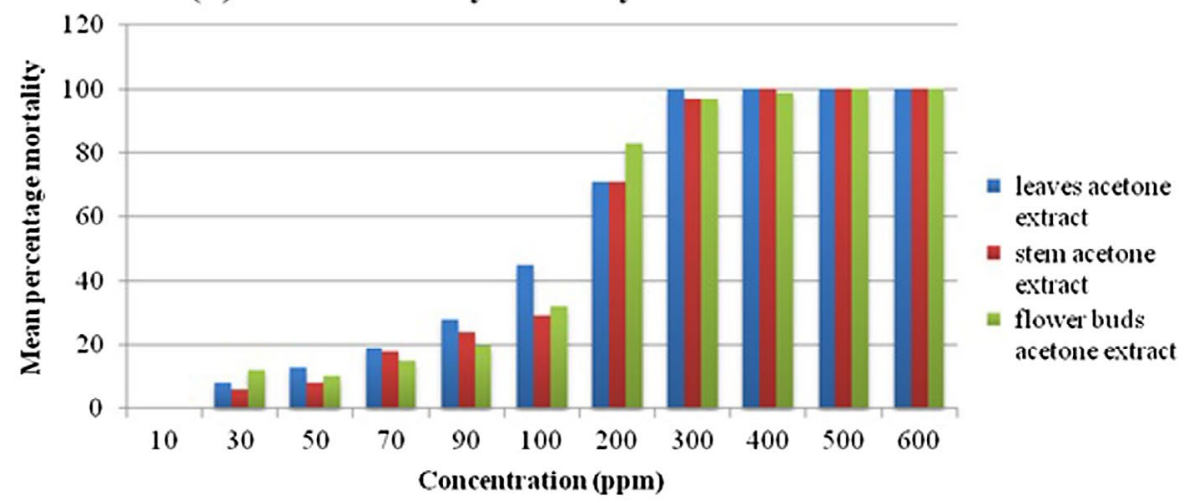

Figure 2. Mean percentage mortality of Culex quinquefasciatus larvae against different concentrations of extracts; (A) Methanol extracts, (B) Acetone extracts, obtained from maceration method. 
(A) Larval mortality caused by methanol extracts.

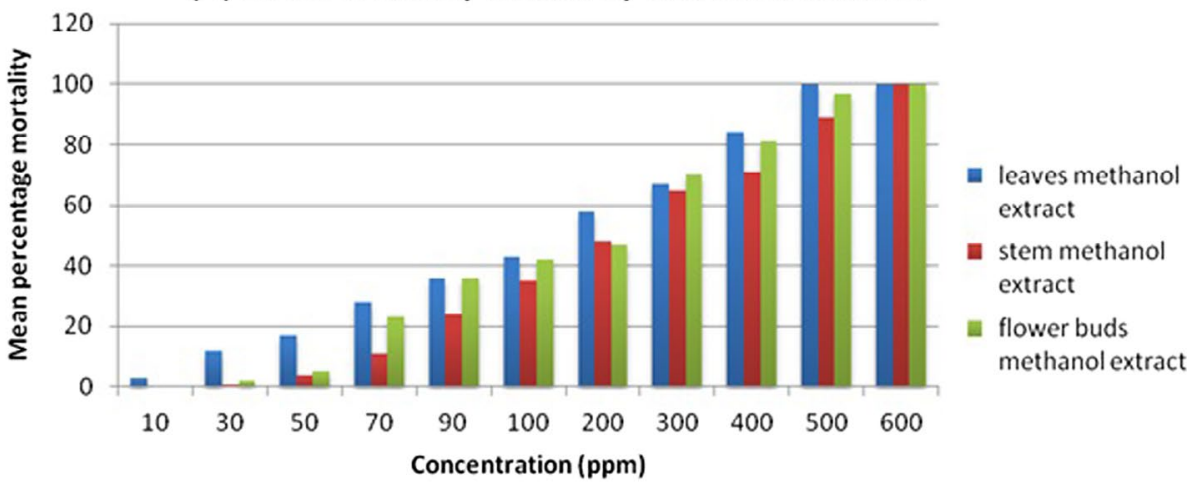

(B) Larval mortality caused by acetone extracts

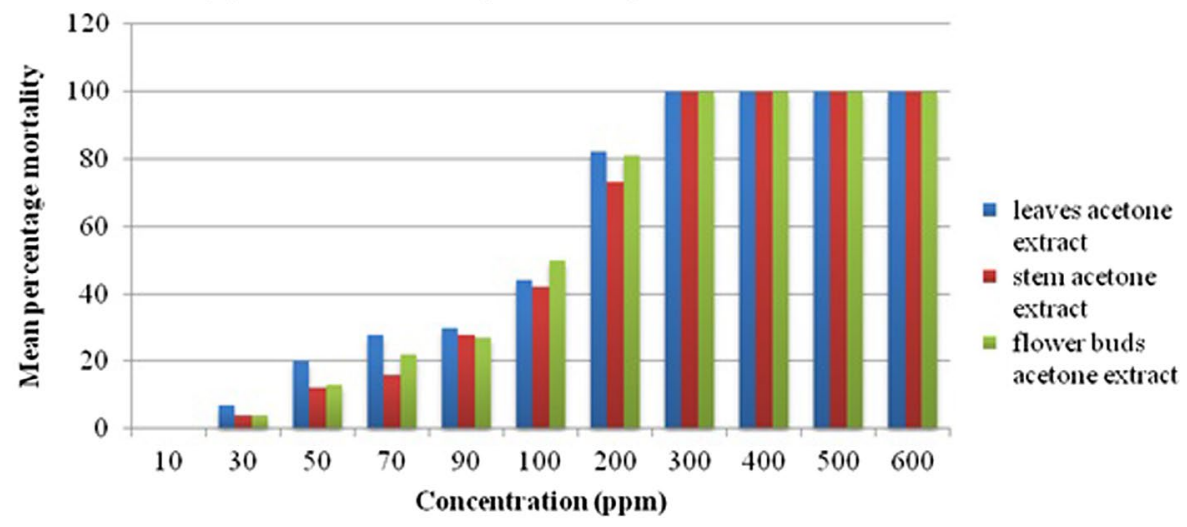

Figure 3. Mean percentage mortality of Culex quinquefasciatus larvae against different concentrations of extracts; (A) Methanol extracts, (B) Acetone extracts, obtained from Soxhlet technique.

Table 2. Lethal concentrations of Ipomoea cairica crude extract of different plant parts against Culex quinquefasciatus larvae.

\begin{tabular}{llcccc}
\hline & & \multicolumn{4}{c}{ Solvent used } \\
\cline { 3 - 6 } & & \multicolumn{3}{c}{ Methanol } & \multicolumn{2}{c}{ Acetone } \\
\cline { 3 - 6 } Methods of extraction & Plant parts used & LC50 (ppm) & LC95 $(\mathrm{ppm})$ & LC50 (ppm) & LC95 (ppm) \\
\hline Maceration & Leaves & 234.601 & 1217.475 & 129.564 & 554.834 \\
& Stem & 235.548 & 1259.032 & 144.533 & 551.401 \\
Soxhlet & Buds & 236.604 & 939.873 & 131.899 & 501.685 \\
& Leaves & 143.466 & 1133.378 & 110.653 & 422.115 \\
& Stem & 191.494 & 1018.312 & 127.989 & 421.348 \\
& Buds & 157.116 & 1259.382 & 113.382 & 336.077 \\
\hline
\end{tabular}

Notes: ppm: parts per million; $\mathrm{LC}_{50}$ - Lethal concentration required to kill $50 \%$ of the population exposed; $\mathrm{LC}_{95}-$ Lethal concentration required to kill $90 \%$ of the population exposed.

obtained from Soxhlet technique presented low LC95 value at $366.077 \mathrm{ppm}$. In general, acetone extracts of the various plant parts studied gives lower LC50 and LC95 values compared to methanolic extracts (Table 2). 
The different plant parts and concentrations of extracts tested also have significant effects on $C x$. quinquefasciatus larval mortality $(\mathrm{F}=2.81, \mathrm{df}=10 p<0.05$; Table 1). The mean percentage mortality calculated clearly shows that with increasing extract concentration from 10 to $600 \mathrm{ppm}$, the larval mortality rate also increase (Figures 2 and 3). At 300 ppm of concentration, leaves acethonilic extract obtained from both Soxhlet and maceration methods showed 100\% mortality. In which, the larvicidal activity was higher compared to other plant part extracts tested as it effectively kills $C x$. quinquefasciatus larvae even at lower concentrations. In other hand, acethonilic extract of stem and flower buds obtained from Soxhlet also exhibited larvicidal properties by causing mortality of the larvae which was observed to be directly proportional to the tested concentrations (Figures 2(B) and $3(B))$. The methanol extracts of the different plant parts also exhibited larvicidal activity at different concentrations, but it was observed to be less effective compared to acetone extracts tested (Figures 2 and 3). No mortality was recorded in the control treatment (distilled water with $1 \%$ methanol or $1 \%$ acetone).

Observations under laboratory condition revealed that after $24 \mathrm{~h}$ treatment with the all extracts tested, the treated larvae expressed behavioural modifications and severe malformations. The treated larvae were found to be restless, wriggled up and down and tend to curl up. These behavioral patterns persisted, causing the larvae to eventually slow down movement, unable to reach the surface and finally resulted in larval knockdown. Observation under stereomicroscope (Olympus EX41), showed dark pigmentation of the cuticle (Figure 4(B) and (C)), disrupted digestive tract (Figure 4(B)) and disruption of the membranous cervix causing detachment of the thorax (Figure $4(\mathrm{C})$ ) of the treated larvae, as compared to the control larvae (Figure 4(A)).

\section{Discussions}

Our study revealed that the acetone extract of $I$. cairica leaves obtained using Soxhlet extraction imposes the most effective larvicidal properties against $C x$. quinquefasciatus larvae compared to maceration method. Using Soxhlet extraction, higher percentage of crude extract yield with greater efficacy of larvicidal ability to kill $C x$. quinquefasciatus larvae can be produced. Soxhlet method had been found to be more effective in extracting larvicidal components for both Azadirachta indica and Artemisia annua Linn compared to reflux and hot extraction methods (Tonk et al. 2006). Comparison of accelerated solvent extraction (ASE) and Soxhlet extraction with conventional maceration showed that the active compound contents were higher using the former two, partly because of the constant higher temperatures used, which result in accelerated diffusion through the plant material (Smelcerovic et al. 2006). The advantages of plant extraction using Soxhlet also include the displacement of transfer equilibrium by repeatedly bringing fresh solvent into contact with the plant powder thus, maintaining a relatively high extraction temperature with heat from the distillation flask (Luque 

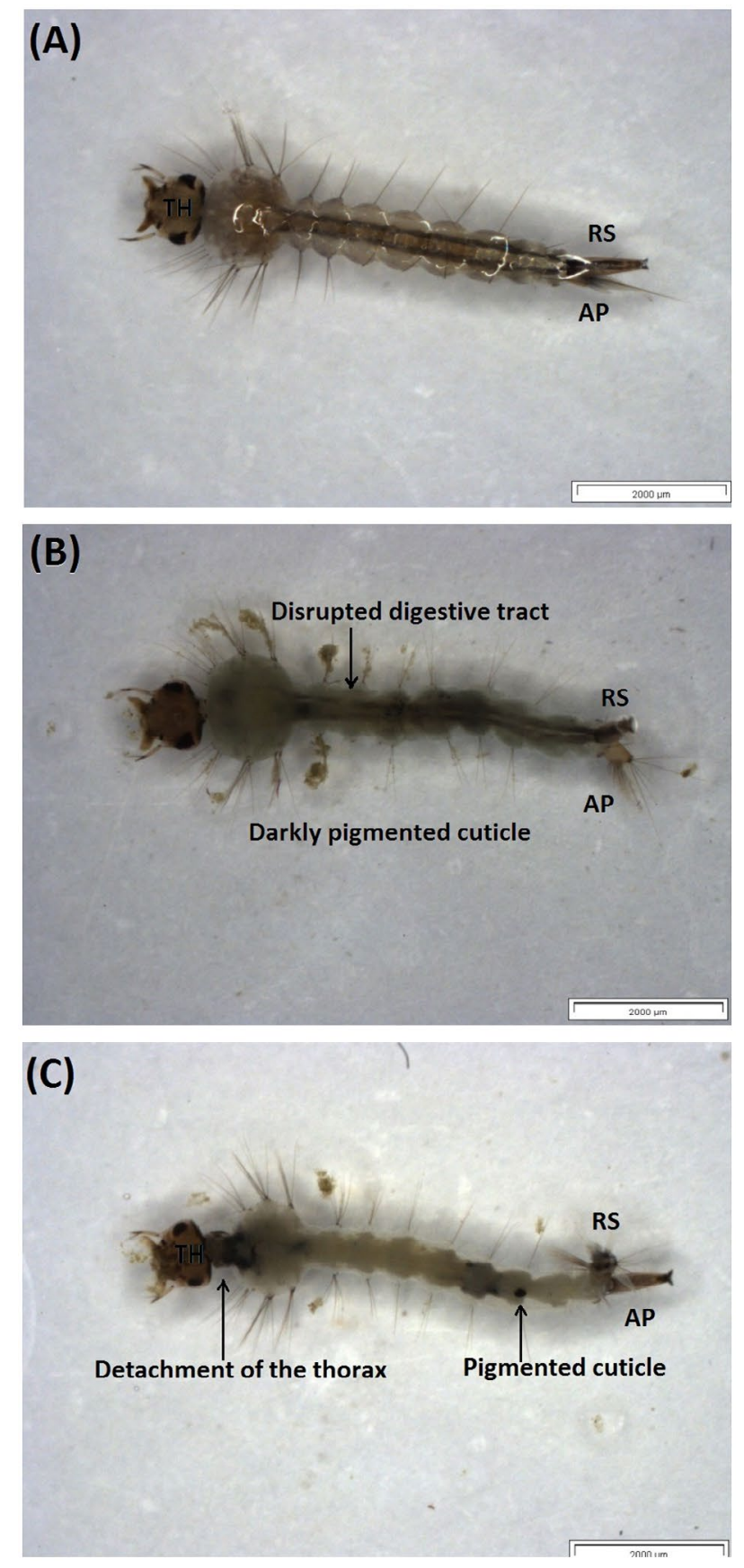

Figure 4. A-C. Morphological malformations in Culex quinquefasciatus larva. A, Culex quinquefasciatus larva observed in control solution; B, Larva with disrupted digestive tract and darkly pigmented cuticle; $C$, Larva with detachment of the thorax and pigmented cuticle observed after exposure to plant extracts tested. Note: THthorax; AP- anal papillae; RS- respiratory siphon. 
de Castro \& Garcia-Ayuso 1998). Other advantages include shortened extraction time and give a better extract yield.

Contrarily, maceration process can be quite time consuming, taking up to several weeks (Jones \& Kinghorn 2006; Trusheva et al. 2007) Exhaustive maceration can also consume large volumes of solvent and can lead to the potential loss of metabolites from plant material. Also, according to the results obtained in the present study, it is shown that less composition of active compound will be extracted and will reduce the efficacy of plant extract as a larvicide. Some compounds may not be extracted efficiently if they are poorly soluble at room temperature. On the other hand, as the extraction is performed at room temperature, maceration is less likely to lead to the degradation of thermolabile metabolites (Jones \& Kinghorn 2006). However, maceration method is as well simple, easy to conduct and relatively cheap since it does not require advance tools.

Yield of crude extract obtained from Soxhlet and maceration methods was different based on the solvents used. Different solvents resulted in different percentage of yield extract and compositions of the active compound (Umuzewa 2003; Zarnowski \& Suzuki 2004). Different organic solvents provided different polarity gradients in dissolving the toxic components present in the plant materials, and also extract greater measures of bioactive components responsible for the lethal effect (Sasidharan et al. 2010). In this study, acetone appeals to be an effective and best solvent in extracting larvicidal compounds from of I. cairica plant. Crude extract obtained from this solvent caused higher mortality of the larvae at lower concentration suggested that the most active compound was extracted. The active compound of the studied plant might be more soluble in acetone than methanol as solvent. Similar results utilised acetone as solvent to extract Lantana camara L. has been found efficient to cause $100 \%$ mortality towards Cx. quinquefasciatus larvae at the dose of $1 \mathrm{~mL} / 100 \mathrm{ml}$ (Dwivedi \& Karwasara 2003).

Higher percentage of yield was obtained from I. cairica leaves, in addition to better larvicidal activity. This suggested that the phytochemical responsible for the toxic effect on Cx. quinquefasciatus larvae may be highly concentrated in the leaves of the studied plant, causing higher mortality of $C x$. quinquefasciatus larvae even at lower concentration. It has been reported in studies done previously, that the bioactivity of phytochemical against mosquito larvae can vary significantly depending on the plant species and their climatic or geographical areas, plant parts, age of plant part, solvent used in the extraction and mosquito species (Tawatsin et al. 2001; Shaalan et al. 2005). The plant materials are not completely homogeneous, which may be one reason for the variations in active compound contents in different extracts from the same plant material (Smelcerovic et al. 2006). Nevertheless, based on the results from the current study, extracts obtained from the stem and flower buds of the studied plant also exhibited larvicidal activity but need a higher concentration to elicit the efficacy effect. Therefore, the active compound responsible for the larvicidal effects can be obtained from various parts of $I$. cairica plant for the control of $C x$. quinquefasciatus larvae. 
The treated larvae were observed to show signs of neurotoxicity, such as ceaselessly moving, curling up, blackening of the abdomen and finally led to death. Effects of seed extract of Seseli diffusum against Ae. aegypti, whereby the larvae exposed to the seed extract also showed similar reactions of restlessness, pigmentation and performed self-biting to the anal papillae with their mouth parts and formed a ring shape (head to siphon) (Kabir et al. 2013). The behavioural changes and morphological malformations in the treated larvae showed the presence of a neurotoxic compound in the plant. The active compound present in the studied plant may have interfered with the metabolic activities of the larvae causing general disruption in the development of larvae and eventually resulted in death.

Phytochemical studies have revealed the presence of the naturally occurring lignanolides, arctigenin and trachelogenin in I. cairica (Lima \& Braz-Filho 1997; Fuss 2003; Umezawa 2003; Meira et al. 2012). Lignans are secondary plant metabolites that occur in all parts of plants, such as heartwood, bark, roots, rhizomes, stems, leaves, flowers, fruits and seeds, as well as in secreted products such as resins and they may be found in the variable content (Ríos et al. 2002). The lignans plays an important part in plant defence mechanism by affording protection against predators such as insects (Fürstenberg-Hägg et al. 2013). Lignan toxicity differs from that of conventional neurotoxic insecticides, as it is more chronic rather than acute (Bernard et al. 1995). Lignan secondary metabolite from phenylpropanoid precursors influence the physiological function including endocrine system of insects (Harmatha \& Dinan 2003).

Essential oil of $I$. cairica has been found to induce $100 \%$ mortality in larvae of Cx. quinquefasciatus, An. stephensi, Ae. aegypti and Cx. tritaeniorhynchus (Thomas et al. 2004). It can be persisted in water and gave an effectiveness up to 21 days (Thiagaletchumi et al. 2014). Essential oils distilled from I. cairica also acted as a promising repellent against $A n$. stephensi and did not cause skin irritation, hot sensations or rashes on the arms of the test volunteers during the study period (Rajkumar \& Jebanesan 2007). Hence, with the following results from the current study, it is sufficient to consider I. cairica for further study focusing on isolation of active principles compound that responsible for the larvicidal properties and assessment in the field for the development of a new alternative mosquito larvicide.

On the whole, the plant extraction using Soxhlet and acetone as solvent gave prominent yield of crude extract with a higher degree of active compound. Among extracts of various parts of I. cairica, the acethonilic leaves extract was found to be the most effective in causing $C x$. quinquefasciatus larvae death. This study also provided further clarification that $I$. cairica plant has larvicidal properties, but its potential as larvicide against mosquito larvae should be researched in depth. The isolation of crude extract to identify the active components and subsequent field trials are required for development of new biopesticides as one of the alternative control methods for insect vectors. These findings will contribute to the practical control of mosquito larvae in the polluted aquatic ecosystem, potable waters and other artificial breeding sites. 


\section{Acknowledgements}

The authors are grateful to the Vector Control Unit and School of Biological Sciences, Universiti Sains, Malaysia for assisting in sample collections and generous supports during the course of the experiment.

\section{Disclosure statement}

No potential conflict of interest was reported by the authors.

\section{Funding}

This project was funded by the Short Term Grant USM [grant number 304/PBIOLOGI/ 6312026].

\section{ORCID}

Wan Fatma Zuharah (D) http://orcid.org/0000-0002-5789-2244

Nik Fadzly (D) http://orcid.org/0000-0002-6282-8423

Sreeramanan Subramaniam (D) http://orcid.org/0000-0003-4392-285X

Zary Shariman Yahaya (D) http://orcid.org/0000-0001-5998-8349

\section{References}

AbuHassan A, Che Salmah MR. 1990. A checklist of the mosquitoes of Malaysia. Journal of Bioscience. 1:29-41.

Bernard CB, Krishanmurty HG, Chauret D, Durst T, Philogène BJR, Sánchez-Vindas P, Hasbun C, Poveda L, San Román L, Arnason JT. 1995. Insecticidal defenses of Piperaceae from the neotropics. Journal of Chemical Ecology. 21:801-814.

Brengues C, Hawkes NJ, Chandre F, Mc Carroll L, Duchon S, Guillet P, Manguin S, Morgan JC, Hemingway J. 2003. Pyrethroid and DDT cross-resistance in Aedes aegypti is correlated with novel mutations in the voltage-gated sodium channel gene. Medical and Veterinary Entomology. 17:87-94.

Chemat S, Lagha A, AitAmar H, Bartels PV, Chemat F. 2004. Comparison of conventional and ultrasound-assisted extraction of carvone and limonene from caraway seeds. Flavour and Fragrance Journal. 19:188-195.

Dwivedi SC, Karwasara K. 2003. Larvicidal activity of five plants extracts against Culex quinquefasciatus. Indian Journal of Entomology. 65:335-338.

Elango G, AbduzZahir A, Bagavan A, Kamaraj C, Rajakumar G, Santhoshkumar T. 2011. Efficacy of indigenous plant extracts on the malaria vector Anopheles subpictus Grassi (Diptera: Culicidae). Indian Journal of Medical Research. 134:375-383.

Fürstenberg-Hägg J, Zagrobelny M, Bak S. 2013. Plant defense against insect herbivore. International Journal of Molecular Science. 14:10242-10297.

Fuss E. 2003. Lignans in plant cell and organ cultures: an overview. Phytochemistry Reviews. 2:307-320.

Harmatha J, Dinan L. 2003. Biological activity of lignans and stillbenoids associated with plant-insects chemical interactions. Phytochemistry Reviews. 2:321-330.

Harwood RF, James MT. 1979. Entomology in human and animal health. New York (NY): Macmillan Publishing. 
Jantan I, Yalvema MF, Ahmad NW, Jamal JA. 2005. Insecticidal activities of the leaf oils of eight Cinnamomum species against Aedes aegypti and Aedes albopictus. Pharmaceutical Biology. 43:526-532.

Jones WP, Kinghorn AD. 2006. Extraction of plant secondary metabolites. In: Sarker SD, Latif Z, Gray AI, editors. Natural Products Isolation. Totowa (NJ): Springer; p. 323-351.

Kabir KE, Choudhary MI, Ahmed S, Tariq RM. 2013. Growth-disrupting, larvicidal and neurobehavioral toxicity effects of seed extract of Seseli diffusum against Aedes aegypti (L.) (Diptera: Culicidae). Ecotoxicology and Environment Safety. 90:52-60.

Kannathasan K, Senthilkumar A, Chandrasekaran M, Venkatesalu V. 2007. Differential larvicidal efficacy of four species of Vitex against Culex quinquefasciatus larva. Parasitological Research. 101:1721-1723.

Karunaratne SH, Hemingway J. 2001. Malathion resistance and prevalence of the malathion carboxylesterase mechanism in populations of mosquito vectors of disease in Sri Lanka. Bulletin WHO. 79:1060-1064.

Lima OODA, Braz-Filho R. 1997. Dibenzylbutyrolactone lignans and coumarins from Ipomoea cairica. Journal of Brazilian Chemical Society. 8:235-238.

Luque de Castro MD, Garcia-Ayuso LE. 1998. Soxhlet extraction of solid materials: an outdated technique with a promising innovative future. Analitica Chimica Acta. 369:1-10.

Mebrahtu YB, Norem J, Taylor M. 1997. Inheritance of larval resistance to permethrin in Aedes aegypti and association with sex ratio distortion and life history variation. Ameican Journal of Tropical Medicine and Hygiene. 56:456-465.

Meira M, Silva EPD, David JM, David JP. 2012. Review of the genus Ipomoea: traditional uses, chemistry and biological activities. Revista Brasileira de Farmacognosia. 22:682-713.

Mohan DR, Ramaswamy M. 2007. Evaluation of larvicidal activity of the leaf extract of a weed plant, Ageratina adenophora, against two important species of mosquitoes, Aedes aegypti and Culex quinquefasciatus. African Journal of Biotechnology. 6:631-638.

Muthukrishnan J, Pushpalatha E, Kasthuribhai A. 1997. Biological effect of four plants extracts on Culex quinquefasciatus say larval stages. International Journal of Tropical Insect Science. 17:389-394.

Nathan SS, Chung PG, Murugan K. 2004. Effect of botanical insecticides and bacterial toxins on the gut enzyme of the rice leaffolder Cnaphalocrocis medinalis. Phytoparasitic. 32:433-443.

Neraliya S, Srivastava US. 1996. Effect of plant extracts on postembryonic development of the mosquito Culex quinquefasciatus. Journal of Advance Zoology. 17:54-58.

Pushpanathan T, Jebanesan A, Govindarajan M. 2008. The essential oil of Zingiber officinalis Linn (Zingiberaceae) as a mosquito larvicidal and repellent agent against the filarial vector Culex. Parasitological Research. 102:1289-1291.

Rahuman AA, Bagavan A, Kamaraj C, Saravanan E, Zahir AA, Elango G. 2009. Efficacy of larvicidal botanical extracts against Culex quinquefasciatus Say (Diptera: Culicidae). Parasitology Research. 104:1365-1372.

Rahuman A, Venkatesan P. 2008. Larvicidal efficacy of five cucurbitaceous plant leaf extracts against mosquito species. Parasitology Research. 103:133-139.

Rajkumar S, Jebanesan A. 2007. Repellent activity of selected plant essential oils against the malarial fever mosquito Anopheles stephensi. Tropical Biomedicine. 24:71-75.

Ríos JL, Giner RM, Prieto JM. 2002. New findings on the bioactivity of lignans'. Studies in Natural Products Chemistry. 26:183-292.

Rongsriyam Y, Trongtokit Y, Komalamisra N, Sinchaipanich N, Apiwathnasorn C, Mitrejet A. 2006. Formulation of tablets from the crude extract of Rhinacanthus nasutus (Thai local plant) against Aedes aegypti and Culex quinquefasciatus larvae: a preliminary study. Southeast Asian Journal of Tropical Medicine and Public Health. 37:265-271. 
Sasidharan S, Chen Y, Saravanan D, Sundram KN, Latha LY. 2010. Extraction, isolation, and characterization of bioactive compounds from plants' extract. African Journal of Traditional, Complementary and Alternative Medicine. 8:1-10.

Shaalan E, Canyon DV, Younes M, Abdel WH, Mansour A. 2005. A review of botanical phytochemicals with mosquitocidal potential. Environment International. 31:1149-1166.

Smelcerovic A, Spiteller M, Zuehlke S. 2006. Comparison of methods for the exhaustive extraction of hypericins, flavonoids, and hyperforin from Hypericum perforatum L. Journal of Agricultural and Food Chemistry. 54:2750-2753.

Tawatsin A, Wratten SD, Scott RR, Thavara U, Techadamrongsin Y. 2001. Repellency of volatile oils from plants against three mosquito vectors. Journal of Vector Ecology. 26:76-82.

Thiagaletchumi M, Zuharah WF, AhbiRami R, Fadzly N, Dieng H, Ahmad AH, AbuBakar S. 2014. Assessment of residual bio-efficacy and persistence of Ipomeoa cairica plant extract against Culex quinquefasciatus Say mosquito. Tropical Biomedicine. 31:466-476.

Thomas T, Rao S, Lal S. 2004. Mosquito larvicidal properties of essential oil of an indigenous plant, Ipomoea cairica Linn. Japanese Journal of Infectious Diseases. 57:176-177.

Tonk S, Bartarya R, Kumari KM, Bhatnagar VP, Srivastava SS. 2006. Effective method for extraction of larvicidal component from leaves of Azadirachta indica and Artemisia annua Linn. Environmental Biology. 27:103-105.

Trusheva B, Trunkova D, Bankova V. 2007. Different extraction methods of biologically active components from propolis: a preliminary study. Chemistry Central Journal. 1:13.

Umezawa T. 2003. Phylogenetic distribution of lignan producing plants. Wood Research: Bulletin Wood Reserach Institute Kyoto University. 90:27-110.

Vaughan A, Chadee DD, Constant RF. 1998. Biochemical monitoring of organophosphorus and carbamate insecticide resistance in Aedes aegypti mosquitoes from Trinidad. Medical and Veterinary Entomology. 12:318-321.

World Health Organization. 2012. Weekly Epidemiological Record. No. 37. 346-356.

World Health Organization. 2005. Guidelines for laboratory and field testing of mosquito larvicide. WHO/CDS/WHOPES/ GCDPP/200513.

Zarnowski R, Suzuki Y. 2004. Expedient Soxhlet extraction of resorcinolic lipids from wheat grains. Journal of Food Composition and Analysis. 17:649-663. 